This item was submitted to Loughborough's Research Repository by the author.

Items in Figshare are protected by copyright, with all rights reserved, unless otherwise indicated.

\title{
Mix design and fresh properties for high-performance printing concrete
}

PLEASE CITE THE PUBLISHED VERSION

http://dx.doi.org/10.1617/s11527-012-9828-z

\section{PUBLISHER}

Springer Verlag ( International Union of Laboratories and Experts in Construction Materials, Systems and Structures (RILEM)

\section{VERSION}

AM (Accepted Manuscript)

\section{LICENCE}

CC BY-NC-ND 4.0

\section{REPOSITORY RECORD}

Le, Thanh T., Simon A. Austin, Sungwoo Lim, Richard A. Buswell, Alistair G.F. Gibb, and Tony Thorpe. 2019. "Mix Design and Fresh Properties for High-performance Printing Concrete". figshare.

https://hdl.handle.net/2134/10930. 
This item was submitted to Loughborough's Institutional Repository (https://dspace.lboro.ac.uk/) by the author and is made available under the following Creative Commons Licence conditions.

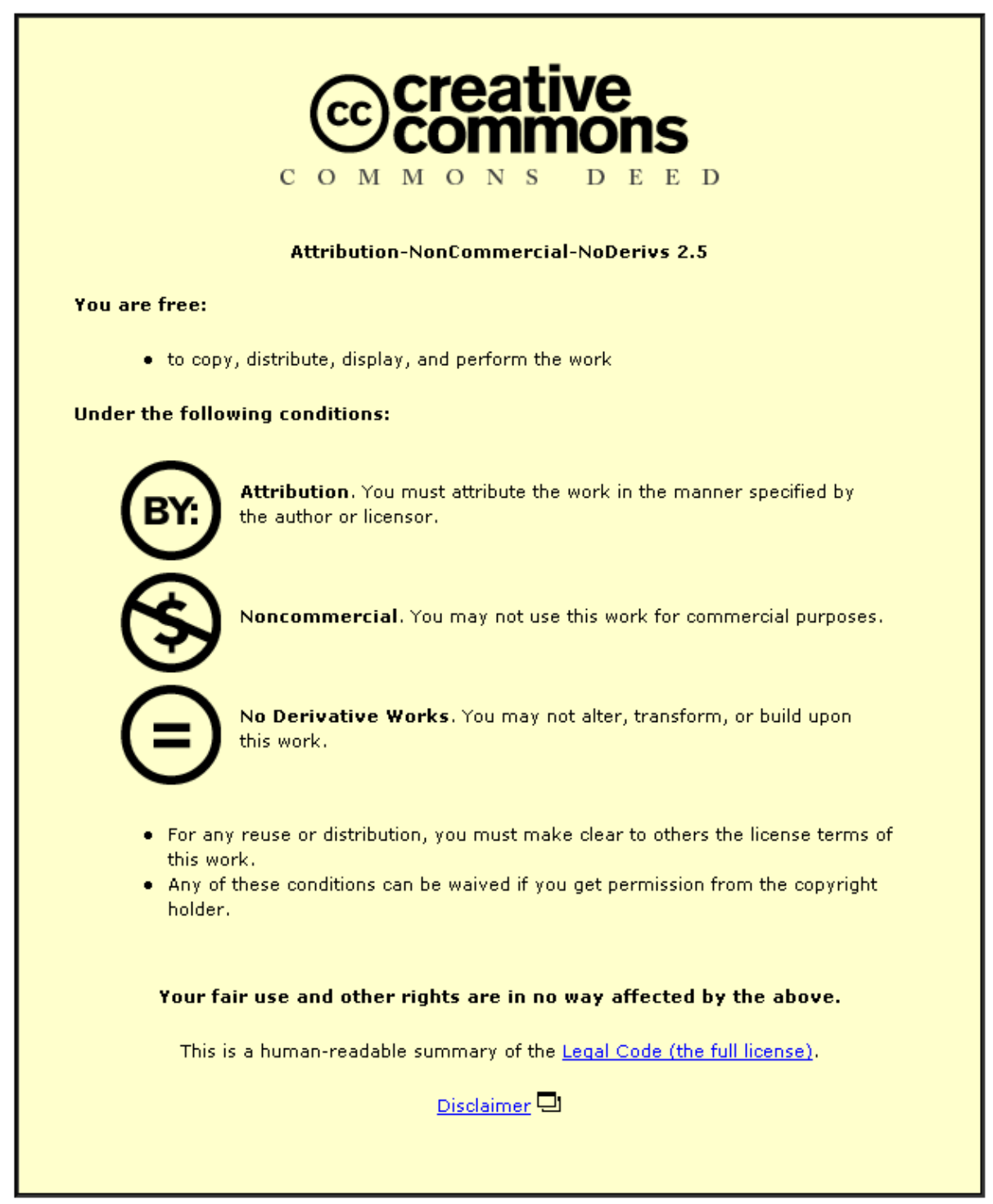

For the full text of this licence, please go to: http://creativecommons.org/licenses/by-nc-nd/2.5/ 


\title{
Mix design and fresh properties for high- performance printing concrete
}

\author{
T. T. Le, S. A. Austin, S. Lim, R. A. Buswell, A. G. F. Gibb, and T. Thorpe
}

Department of Civil and Building Engineering, Loughborough University, Loughborough, Leicestershire, LE11 3TU, United Kingdom

\begin{abstract}
This paper presents the experimental results concerning the mix design and fresh properties of a high-performance fibre-reinforced fine-aggregate concrete for printing concrete. This concrete has been designed to be extruded through a nozzle to build layer-by-layer structural components. The printing process is a novel digitally-controlled additive manufacturing method which can build architectural and structural components without formwork, unlike conventional concrete construction methods. The most critical fresh properties are shown to be extrudability and buildability, which have mutual relationships with workability and open time. These properties are significantly influenced by the mix proportions and the presence of superplasticiser, retarder, accelerator and polypropylene fibres. An optimum mix is identified and validated by the full-scale manufacture of a bench component.
\end{abstract}

Key words: additive manufacturing, build, concrete, extrusion, open time, printing.

\section{Introduction}

Concrete is normally placed into formwork and then vibrated to fabricate building components. Two alternative construction strategies - self-compacting and sprayed concretes - have been developed to eliminate the compaction process. The basic principle of self-compacting concrete is that aggregate particles form a smooth grading with a minimum void content and a considerable volume of cementitious paste with a superplasticiser, which fill the gap between aggregate particles to create flowability $[1,2]$. However, concrete construction using selfcompacting concrete still has to use formwork which needs considerable time and 
labour for setting up and constrains geometries to minimise the materials cost by re-using the forms.

Sprayed concrete $[3,4]$ is another approach to making concrete components usually using a backing material (natural, like rock, or man-made) to eliminate temporary formwork. The mix proportions are designed for a minimum voids by a grading with the largest size particles filled with particles of the next size fraction down, and so on. This is particularly important with the wet process to facilitate plug flow in the delivery hose [4] and is achieved by using a combined grading (aggregate, cement and powdered additions). A relatively high cement content is needed to facilitate adhesion and build-up thickness and form a lubricating layer around the inside of conveying pipes. This is also to make sure that the mix can be pumpable and sprayable. Formwork is reduced when using this method but the shape and form of building components is not precise.

Concrete printing is an innovative construction process for fabricating concrete components employing an additive, layer-based, manufacturing technique, also called freeform construction $[5,6]$. This method can be used to build complex geometrical shapes without formwork, and thus has a unique advantage over conventional construction methods. Briefly, components are designed as volumetric objects using 3D modelling software. They are next sliced and represented as a series of two dimensional layers. The data are exported to a printing machine layer-by-layer in order to print structural components by the controlled extrusion of a cementitious material. The potential advantages of this process include: (a) integration of mechanical and electrical services within voids formed in the structure could optimise materials usage and site work; (b) better control of the deposition of build material can produce novel internal and external finishes; (c) creating integrated units will reduce interface detailing and hence the likelihood of costly remedial works; and (d) the coupling of a layered construction process with solid modelling techniques will give greater design freedom.

The development of a printing concrete is reported to exploit the potential of this advanced method of construction. The concrete needs to have an acceptable degree of extrudability to be extruded through a printing head containing nozzles to form small concrete filaments. The filaments must bond together to form each 
layer, as the fresh concrete is continuously extruded to form consecutive filaments layered on the previous ones to build complete 3D components. Furthermore, the material must have sufficient buildability characteristics to enable it to lay down correctly, remain in position, be stiff enough to support further layers without collapsing and yet still be suitable to provide a good bond between layers. A high strength (of the order of $100 \mathrm{MPa}$ in compression) was targeted in this research because the layered structure of components fabricated by this method is likely to be inherently weaker than conventional in-situ and precast concrete.

In principle, printing concrete has the advantages of both self-compacting concrete (i.e. self-compacting without any assistance of vibration) and sprayed concrete (i.e. fresh concrete is expelled from a nozzle to fabricate complex forms) to meet the critical requirements of a freeform construction process. The selfcompacting performance of a printing concrete is dependent on the ability to extrude consistent filaments while the use of wet-process sprayed concrete principles can help ensure that the fresh concrete is conveyed effectively in the pipe and pump system without blocking. An additional requirement is the ability to build layers without significant deformation due to self-weight before setting.

A systematic research programme and experimental results are presented to identify optimum mix proportions together with the ways developed to control and measure the fresh properties, namely extrudability, workability, open time and buildability.

\section{Concrete printing process}

The prototype concrete printing machine operates within a $5.4 \mathrm{~m}$ (length) $\mathrm{x} 4.4 \mathrm{~m}$ (width) $\times 5.4 \mathrm{~m}$ (height) steel frame (see Fig. 1). The system comprises a printing head which is digitally controlled by a CNC machine to move in $\mathrm{X}, \mathrm{Y}$ and $\mathrm{Z}$ directions via three chain-driven tubular steel beams. A material container is mounted on top of the printing head and connected to a pump to convey the material to the printing nozzle which is activated by the $\mathrm{CNC}$ machine. 


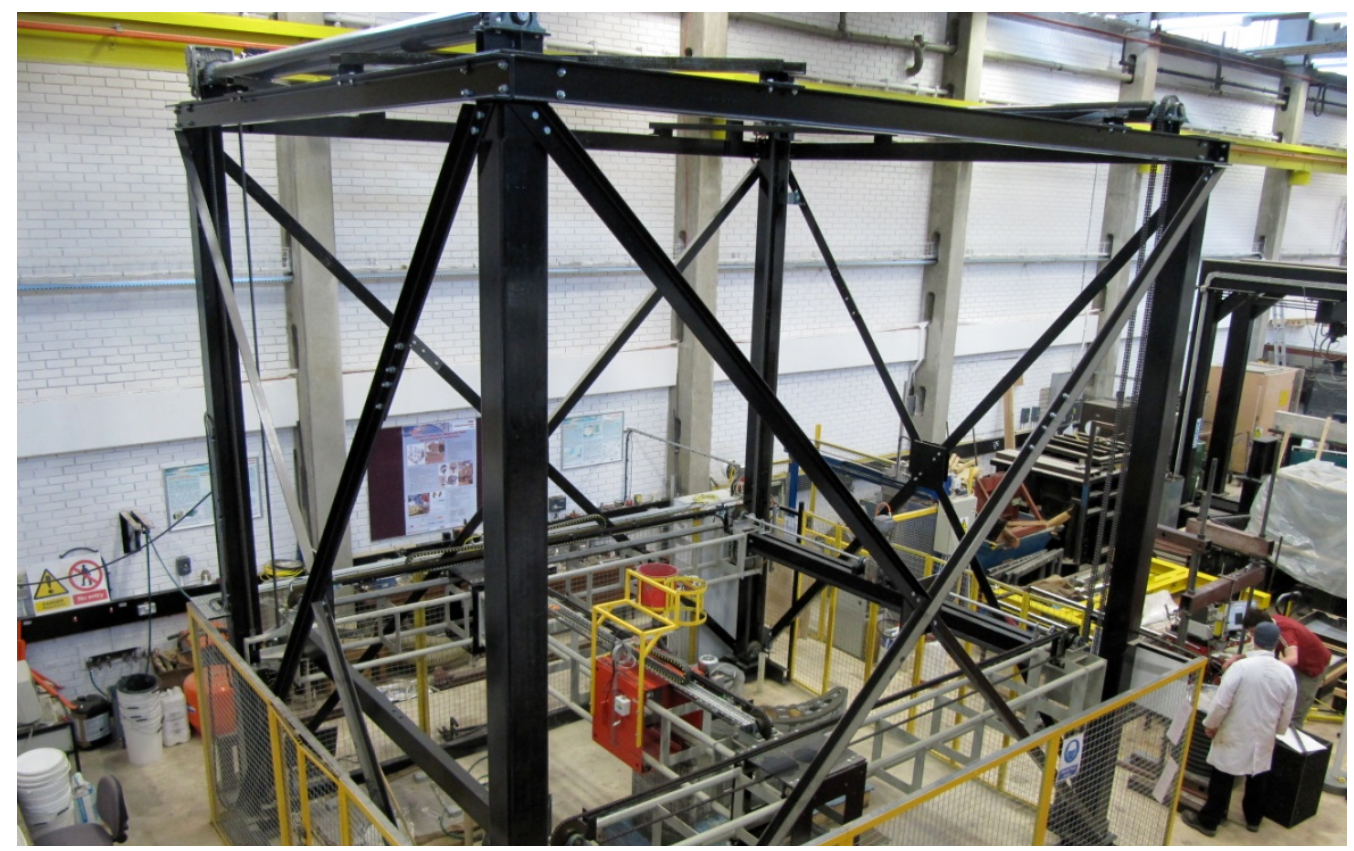

Fig. 1. Concrete printing system

The printing process is in three stages: data preparation, concrete preparation, and component printing. In the data preparation stage a component is designed as a $3 \mathrm{D}$ CAD model, then converted to an STL file format and sliced with a desired layer depth. The printing path for each layer is then generated to create a G-Code file for printing. Concrete preparation involves mixing and placing it into the container. Once the fresh concrete has been placed into the container, it can be conveyed smoothly through the pump-pipe-nozzle system to print out selfcompacting concrete filaments, which can build layer-by-layer structural components. The schematic in Fig. 2 shows the delivery system of the concrete printing process. 


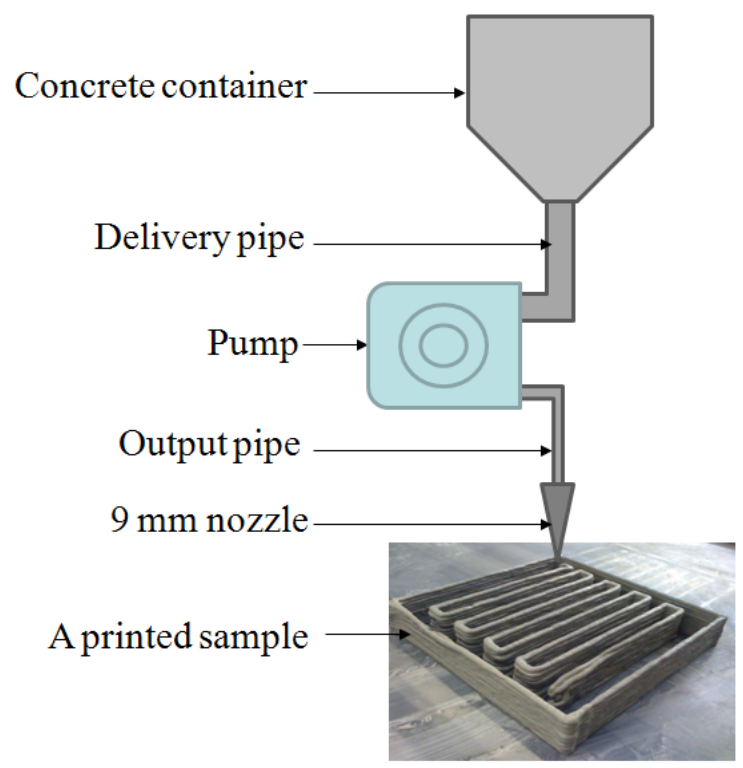

Fig. 2. Schematic of concrete delivery system

Experiments showed that the most critical properties in the fresh state of this printing process are extrudability and buildability. Extrudability can be defined as the capacity of concrete to pass through the small pipes and nozzles at the printing head. It is principally influenced by the workability (consistence) of the concrete and mix proportions (i.e. cementitious binder/aggregate ratio, water/binder ratio, admixture usage). Good extrudability was achieved by applying the principles of self-compacting concrete and sprayed concrete to the mix design. Once the fresh concrete passes the extrudability criteria, it can draw self-compacting filaments which have an elliptical cross section.

More demanding than self-compacting concrete, the printed filaments should be formed with minimal deformation under the weight of subsequent layers. Additionally, the lower filaments should bond to the upper ones to build monolithic components. Thus, this high-performance concrete requires a buildability which relates to the capacity to print a certain number of layers or height. Buildability also depends on the workability and mix proportions and in particular the variation in workability with time, i.e. open time. There is a dilemma here in that the workability needed to maintain a consistent flow rate for good extrudability requires a long "open time". Otherwise the material becomes stiffer and results in slowing down the flow rate and printing speed and possibly causing blockage. On the other hand, a long open time extends the extrudability 
and helps inter-layer bonding but could be detrimental to the layer deformation aspect of buildability. Thus the two key properties of extrudability and buildability are underpinned by knowledge of the process-independent properties of workability and open time.

\section{Experimental Programme and Methods}

The experimental programme comprised: (a) mix design; (b) investigations of the effect of mix proportions with admixtures on the fresh properties; and (c) printing a large-scale freeform component to evaluate the feasibility of the printing concrete working with the concrete printing machine.

\subsection{Materials and mix design}

The mix design of concrete needed to meet the performance requirements of the fresh and hardened concrete. The performance of the former comprises extrudability and buildability which are significantly influenced by the workability and open time. The key properties of the hardened concrete are the compressive and flexural strengths of both cast and printed specimens. Initially, targets of compressive strength of $100 \mathrm{MPa}$ and flexural strength of $12 \mathrm{MPa}$ at 28 days were set for mould-cast specimens.

A $2 \mathrm{~mm}$ maximum size sand was selected because of the small nozzle diameter (i.e. $9 \mathrm{~mm}$ ) to give a high printing resolution. Cement CEM type I 52.5, fly ash and undensified silica fume formed the binder component. The gradings, measured by a Mastersizer 2000 machine, of sand, cement, fly ash and silica fume were combined in various proportions to form smooth grading curves of test mixtures. The dry components were added to the mixing water together with a polycarboxylate based superplasticiser to lower the water/binder ratio and hence increase its workability as well as strength. A retarder, formed by amino-tris (methylenephosphonic acid), citric acid and formaldehyde, was added to maintain a sufficient open time, facilitating a constant flow during printing stages. An accelerator, formed by sulphuric, aluminium salt and diethanolamine, was also investigated to control setting. The concrete contained $12 / 0.18 \mathrm{~mm}$ 
length/diameter polypropylene micro fibres to reduce shrinkage and deformation in the plastic state. The optimum mix was considered to be the one with the lowest content of binder that could be printed and built with the recommended dosage of fibres from the supplier (i.e. $1.2 \mathrm{~kg} / \mathrm{m}^{3}$ ) and gain the target strengths.

\subsection{Experimental procedures}

First, preliminary mixtures were tested for extrudability to find the optimum particle grading which include sand, cement, fly ash and silica fume. Then, the mix with optimum particle composition was tested with fibres and the admixture dosages varied to approach the optimum extrudability, workability, open time and buildability. The methods used to measure the fresh properties are described as follows. The strategy was to use very practical indications of successful printing, in terms of the ability to extrude filaments into a layer (extrudability) and to then build-up multiple layers (buildability). This allows an appropriate mix design to be established. We then adopted shear strength, and its change with time, (to define workability and open-time) to characterise the material scientifically and allow a mix to be fine-tuned.

\subsubsection{Extrudability}

Extrudability here relates to the ability to transport the fresh concrete through a hopper and pumping system to a nozzle where it must be extruded as a continuous filament. Earlier research concerning this ability referred to the pumping and spraying of concrete $[3,4,7]$, but the fresh concrete exits the system as a particle stream, not an extrusion. Extruding concrete to build components has been mentioned in previous research [8-11] but a suitable test method to evaluate this ability of concrete has not been described.

In this research, the extrudability was evaluated with $9 \mathrm{~mm}$ wide filaments (printed from a $9 \mathrm{~mm}$ nozzle) that comprised five groups from one to five filaments as shown in Fig. 3. Each filament was $300 \mathrm{~mm}$ long and the total continuous length of filaments extruded out for a test was $4,500 \mathrm{~mm}$. The test shape was designed to represent the typical way of building freeform construction 
components. The test result was evaluated as YES or NO, the former being when the complete length of $4,500 \mathrm{~mm}$ was deposited successfully without a blockage or fracture.

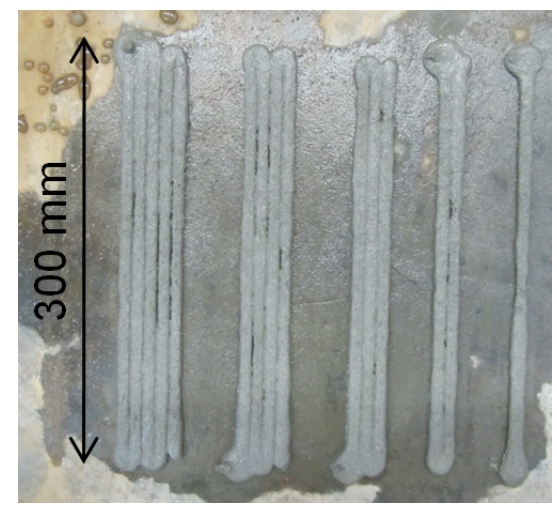

Fig. 3. Test sample to evaluate extrudability

\subsubsection{Workability}

Conventional methods evaluating workability include slump, compacting factor and flow tests, for which various national standards are available. However, these do not measure fundamental physical properties. An alternative approach is to conduct a more robust rheological investigation, such as a two-point test (e.g. Tattersall [12]) which can characterise Bingham fluid behaviour in terms of shear strength and torque viscosity. Such methods have their own difficulties (especially in calibration) and cannot be conducted in-situ. Austin et al. [3, 4, 7] adopted a shear vane apparatus (originally for measuring the shear strength of soils) to measure the workability of concrete. This approach was adopted because it derives a relevant, scientific rheological parameter (unlike, say slump) and can also evaluate the workability at various points in the production process including the mixer and container [7]. The shear strength of the concrete can be determined from the maximum torque according to BS 1377-9:1990 [13]. A $90 \mathrm{~mm}$ diameter vane was used in this research because of the relatively low shear strength, where the factor to convert the outer reading of the shear vane apparatus to shear strength is 0.022 . This is the method used in this research. To avoid boundary effects, a container with the dimensions detailed in Fig. 4 was used in all shear vane tests. In each test, three measurements were taken in the positions shown with the average representing the result of one shear vane test. 

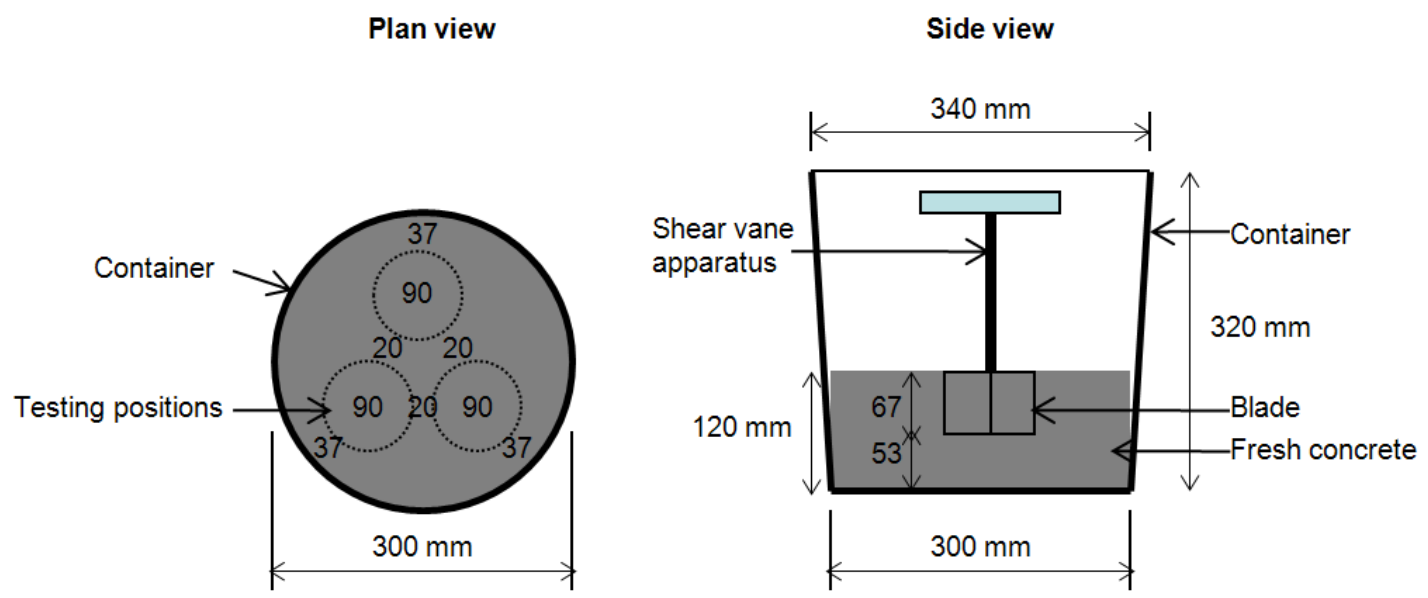

Fig. 4. Diagram of a shear vane test with measuring positions

\subsubsection{Open time}

The open time of a cementitious material has a relationship with its setting time, usually measured with a Vicat apparatus. However, this equipment is designed to determine the initial and final setting time which are not particularly helpful in characterising the change of workability with time of fresh concrete.

Various research investigations have been carried out to monitor the change of workability with time using a slump test [14-17]. For example, the slump loss of polynapthalene-sulfonates superplasticised cement pastes with time (up to 90 minutes) was investigated using a mini cone apparatus in a research carried out by Kim et al. [16], while Alhozaimy [17] used the ASTM C143 standard cone apparatus to measureslump at $15,30,60,90,120$, and 150 minutes after measuring the initial slump of a concrete containing limestone powder to investigate the slump loss phenomenon. These investigations have introduced a preliminary definition concerning open time that the time period in which the fresh concrete is still reasonably workable. However, using the slump test in this printing concrete research is not suitable for the reasons discussed in section 3.2.2. Measuring the change of shear strength (workability) with time with a shear vane apparatus was considered to be more informative. 
The open time in this research, was determined as the time period in which the workability of fresh concrete was at a level that maintained extrudability. The ending of open time was found to be once the shear strength had increased by 0.3 $\mathrm{kPa}$ from the initial shear strength of the concrete as this increase in shear strength, i.e. decrease in workability, was found to coincide with increasing difficulty of printing a good quality filament (with an optimum mix). The workability of fresh concrete was therefore measured every 15 minutes using the shear vane to determine the open time. Preliminary tests showed that fresh concrete samples usually had higher shear strength if they were not agitated before testing. As a result, shear strength was tested in two ways: the first measurement was done with non-agitated samples and the samples were then agitated by shaking the container 10 times and the second measurement taken (i.e. agitated sample).

\subsubsection{Buildability}

Most concrete is placed into formwork as a fluid and there is no need for it to be self-supporting, i.e. the buildability is not an issue. Sprayed concrete is an exception, and research quantifying the buildability of a mix has been done by Austin et al. [7]. The work focused on estimating the adhesion and cohesion of sprayed concrete in a horizontal build test. The horizontal build is not appropriate for the current process. In absence of other methods, the buildability of fresh concrete was quantifying as the number of filament layers which could be built up, based on the shape used to evaluate the extrudability, without noticeable deformation of lower layers.

\section{Results and Discussions}

\subsection{Mix design}

Five preliminary mixes with different sand/binder proportions were designed by combining their particle analysis results, see Fig. 5. The sand content was reduced in 5\% increments from $75 \%$ to $55 \%$ by weight of dry mixture in Mix 1 to Mix 5 whilst the binder content was increased from $25 \%$ to $45 \%$, respectively. The 
binder in all mixes comprises $70 \%$ cement, $20 \%$ fly ash and $10 \%$ silica fume. A water-binder ratio of 0.28 was selected to achieve over $100 \mathrm{MPa}$ compressive strength concrete based upon a previous study of ultra high performance concrete [18].

A pumpable sprayed mortar [3] and a commercial pre-packaged mortar [19] are also shown for comparison. The percentage passing $0.6 \mathrm{~mm}$ was over $95 \%$ for all mixes, whilst the reference sprayable mixes were in the range of $83-90 \%$. The printing mixes were made finer to be more suited to deposition through the $9 \mathrm{~mm}$ diameter nozzle.

The mix proportions of five preliminary mixes were calculated assuming a density of $2300 \mathrm{~kg} / \mathrm{m}^{3}$ (Table 1). The dosages of superplasticser, retarder, accelerator and polypropylene fibres were varied to identify optimum mix proportions for printing.

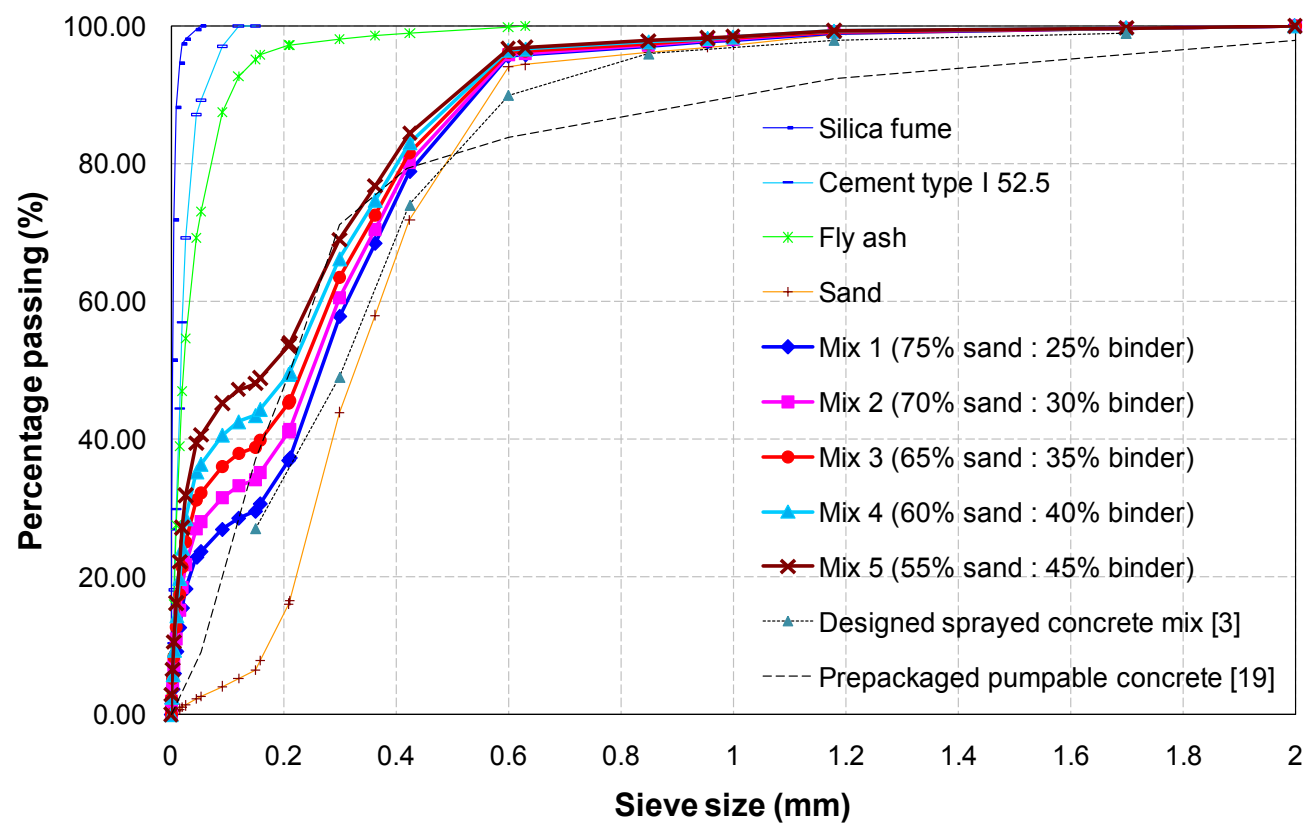

Fig. 5. Particle size distribution of mixes 
Table 1. Mix proportions of the trial mixes

\begin{tabular}{llllll}
\hline \multirow{2}{*}{ Material } & \multicolumn{5}{c}{ Mix proportions $\left(\mathrm{kg} / \mathrm{m}^{3}\right)$} \\
& Mix 1 & Mix 2 & Mix 3 & Mix 4 & Mix 5 \\
& & & & & \\
\hline Sand & 1612 & 1485 & 1362 & 1241 & 1123 \\
Cement & 376 & 446 & 513 & 579 & 643 \\
Fly ash & 107 & 127 & 147 & 165 & 184 \\
Silica fume & 54 & 64 & 73 & 83 & 92 \\
Water & 150 & 178 & 205 & 232 & 257 \\
\hline
\end{tabular}

\subsection{Extrudability}

The extrudability was affected significantly by the combination of particle sizes of the constituent materials. Mixes 1 and 2 were difficult to pass through the pipepump-nozzle system due to the high sand content that caused sand segregation. More water and superplasticiser were added to make them more flowable but the concrete still segregated in the pipes which led to blocking. The binder content of 25 and $30 \%$ in these mixes appear to be insufficient to create a suitable extrudability to cope with this printing process.

$1-2 \%$ superplasticiser was also added in Mixes 3 and 4 to improve the extrudability. They could be extruded from the nozzle and printed. However, Mix 4 was more suitable when incorporating micro polypropylene fibres as it could be printed with up to $1.6 \mathrm{~kg} / \mathrm{m}^{3}$ while Mix 3 could only be printed with a fibre dosage of up to $0.4 \mathrm{~kg} / \mathrm{m}^{3}$. Above these dosages the $9 \mathrm{~mm}$ diameter nozzle became blocked. As Mix 4 passed the extrudability criteria with a fibre dosage over that of $1.2 \mathrm{~kg} / \mathrm{m}^{3}$ recommended from the fibre supplier, it was identified as the optimum mix in terms of extrudability and binder content. Mix 5 , which had even higher binder content, was therefore not evaluated further.

Concerning the effect of workability on the extrudability, a shear strength in the range of 0.3 to $0.9 \mathrm{kPa}$ (controlled by superplasticiser dosage) was optimum for printing Mix 4. Lower than $0.3 \mathrm{kPa}$, the fresh concrete was too wet and 
segregation occurred in the pipe-pump-nozzle system. The concrete filaments extruded out were deformed with unstable cross sections. Above $0.9 \mathrm{kPa}$, the fresh concrete was too stiff for printing and could not finish the extrudability shape of 4,500 $\mathrm{mm}$. The concrete filaments extruded out of the nozzle fractured and the mix could not be printed continuously.

The cross section of extruded filaments had an elliptical shape. Mix 4, with an initial shear strength of $0.55 \mathrm{kPa}$ ( $1 \%$ superplasticiser and the water to binder ratio of 0.26 as the water content was reduced from $232 \mathrm{~kg} / \mathrm{m}^{3}$ to $216 \mathrm{~kg} / \mathrm{m}^{3}$ to obtain the best extrudability), gave consistent filaments with a cross section of approximately $9 \mathrm{~mm}$ transverse diameter and $6 \mathrm{~mm}$ conjugate diameter. Mixes using $1.5-2 \%$ superplasticiser appeared too wet (initial shear strength of $0.2-$ $0.4 \mathrm{kPa}$ ) and led to deformed concrete filaments. However, using $1 \%$ superplasticiser resulted in a mix which could not be printed 30 minutes after mixing. Therefore a retarder was added to extend the time for extrudability, i.e. open time.

As Mix 4 was the optimum in terms of extrudability, it was subsequently used to investigate and optimise the other fresh properties, i.e. workability, open time and buildability.

\subsection{Workability}

The workability was influenced significantly by the dosage of superplasticiser, retarder and accelerator. In the series without retarder and accelerator, increasing the superplasticiser dosage from 0 to $2 \%$ by weight of binder increased the workability, i.e. reduced the shear strength, see Fig. 6. The workability of Mix 4 with $0 \%$ superplasticiser could not be determined as the concrete was too stiff. To achieve a measurable workability (shear strength of $2.24 \mathrm{kPa}$ ) for this $0 \%$ superplasticiser mix, the water-binder ratio was increased up to 0.36 and then to 0.44 to gain a shear strength of $0.57 \mathrm{kPa}$ for printing. The superplasticiser thus proved crucial for printing concrete to attain a reasonable workability and also to attain high strength with a low water-binder ratio. 
A big change occurred between 0.5 to $1.0 \%$ superplasticiser dosages, the shear strength decreasing from $2.60 \mathrm{kPa}$ to $0.55 \mathrm{kPa}$ (Fig. 6). Mix 4 with $0.5 \%$ superplasticiser was too stiff for printing while 1.5 to $2.0 \%$ superplasticiser was likely to result in deformed concrete filaments. Therefore, Mix 4 with 1\% superplasticiser was selected to be the control mix to investigate the effect of retarder and accelerator dosage on the workability and open time of printing concrete.

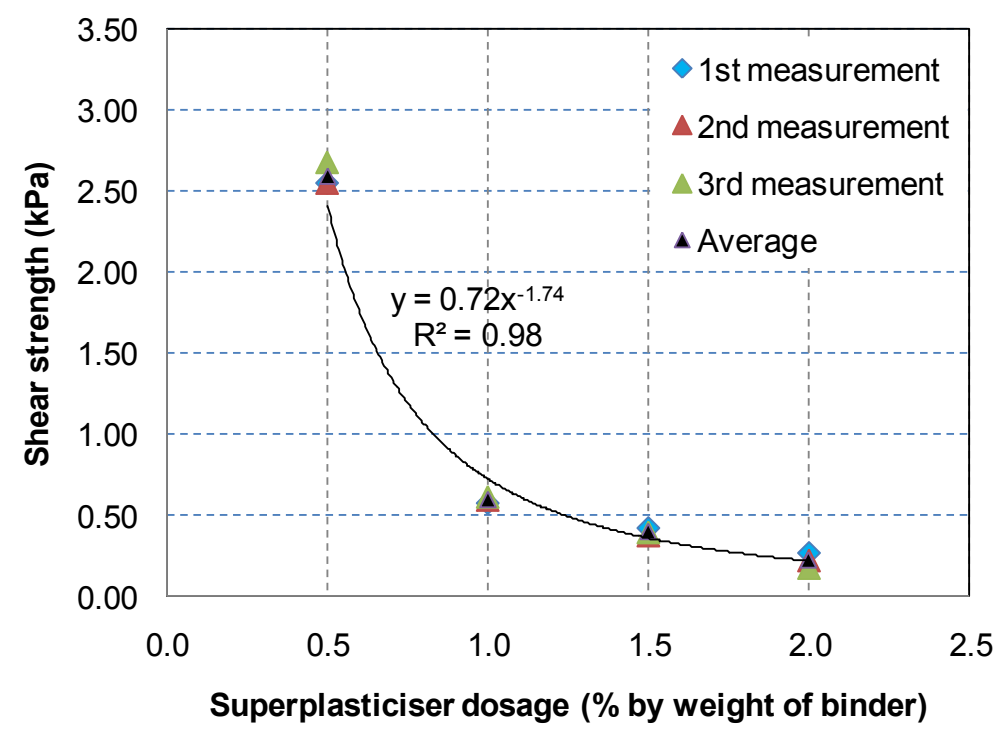

Fig. 6. Effect of superplasticiser dosage on workability

Unlike the effect of superplasticiser on the workability of the printing concrete, increasing the retarder or accelerator dosage reduced the workability, i.e. increased the shear strength. The trend of changing workability caused by the retarder appeared linear, while that due to accelerator appeared nonlinear (quadratic form), see Fig. 7 and Fig. 8. Accelerator was tested here with an aim that it would be used at the nozzle, i.e. before extrusion, to control the setting during the printing process. 


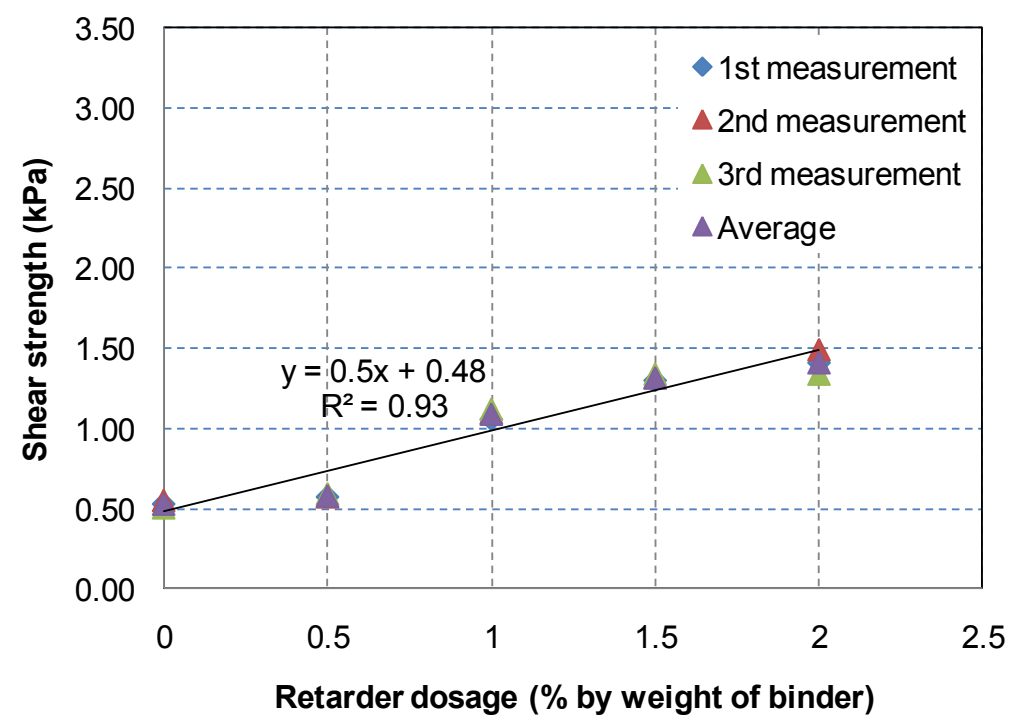

Fig. 7. Effect of retarder dosage on workability

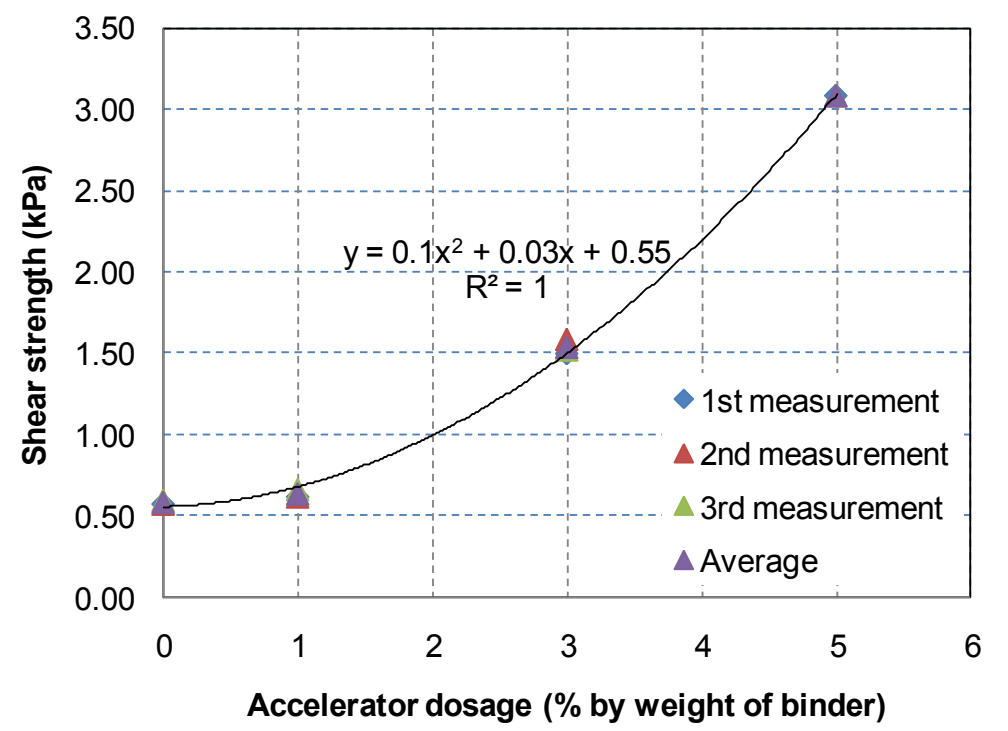

Fig. 8. Effect of accelerator dosage on workability

\subsection{Open time}

The open time was investigated first with varying superplasticiser and no retarder and secondly with varying retarder and 1\% superplasticiser (based on the results of first set).

Fig. 9 shows the effect of superplasticiser dosages, from $0-2 \%$ by weight of binder, on the workability with time. The open time (when shear strength increased by $0.3 \mathrm{kPa}$ ) of the non-agitated samples was very short (Fig. 10, 
determined from Fig. 9). The $0.5 \%$ superplasticiser sample had only 3 minute open time with the initial shear strength of $2.6 \mathrm{kPa}$, but after 13 minutes the shear strength could not be measured because it exceeded the capacity of the shear vane apparatus $(3.2 \mathrm{kPa})$. Less than 5 minutes open time was obtained with $1 \%$ superplasticiser and $1.5-2.0 \%$ superplasticiser only extended the open time up to $15-18$ minutes.

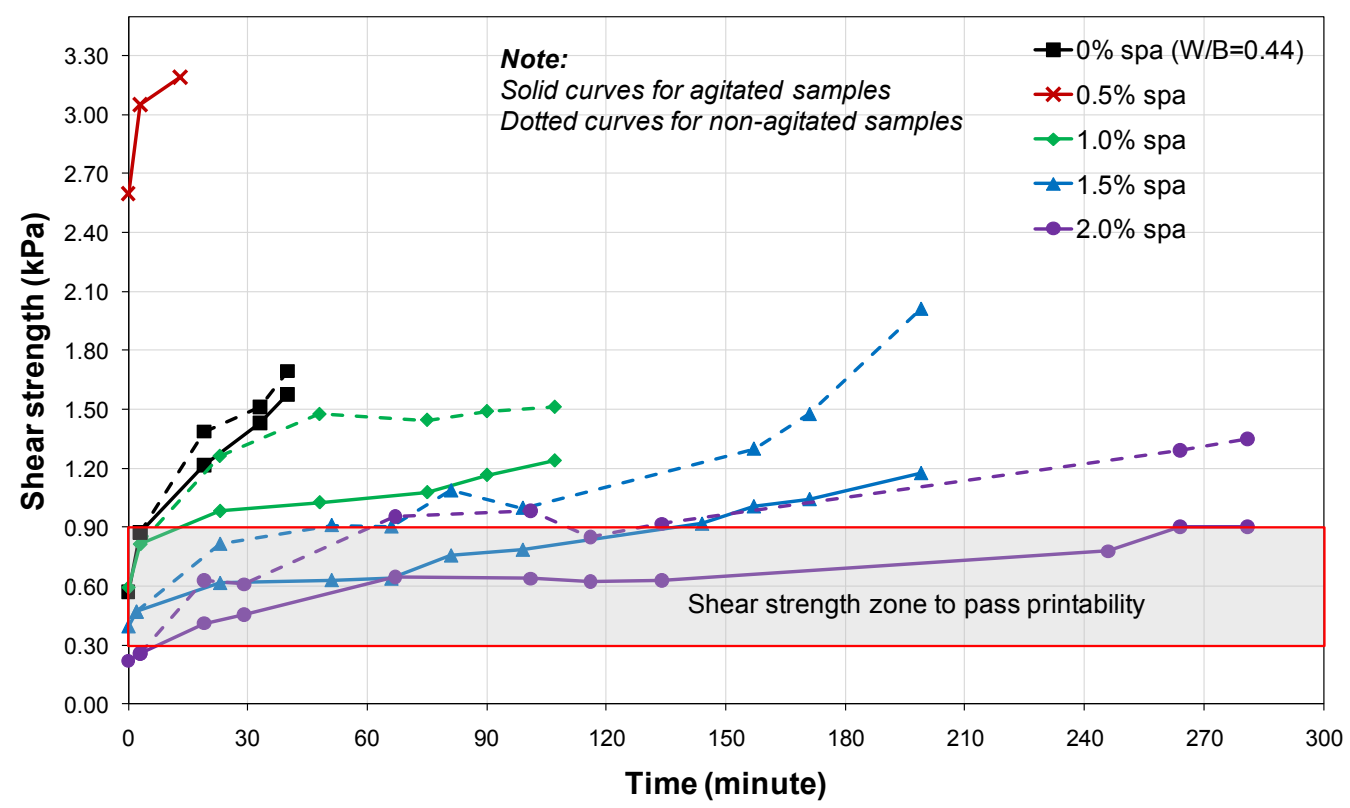

Fig. 9. Effect of superplasticiser dosage on workability with time

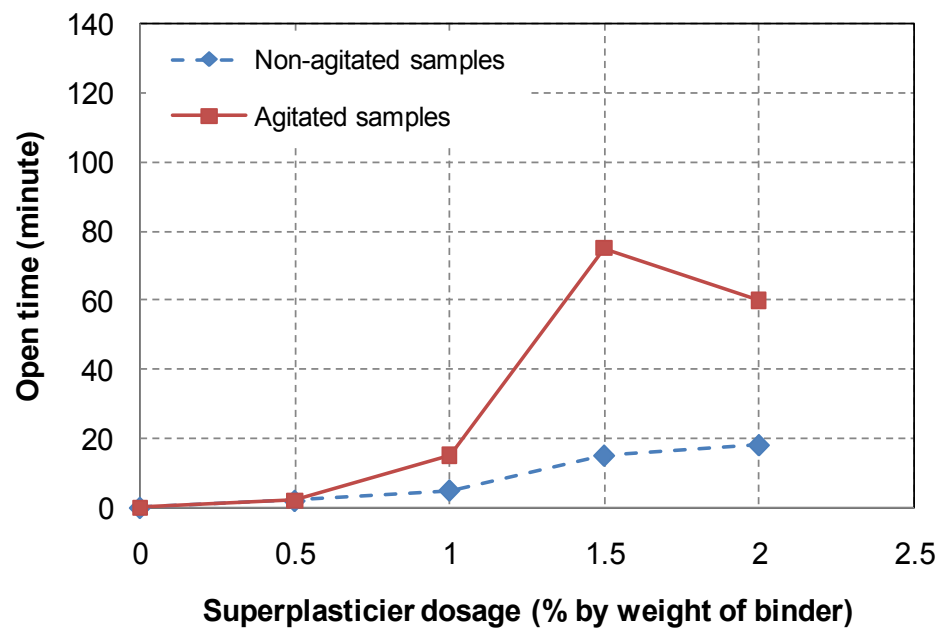

Fig. 10. Superplasticiser dosage versus open time 
Agitated samples had longer open time. 1\% superplasticiser needed approximately 15 minutes to increase the shear strength by $0.3 \mathrm{kPa}$ while $1.5-2.0 \%$ needed over 60 minutes (Fig. 10). However, using high dosage of superplasticiser would result in deformed filaments as discussed previously, i.e. reducing the buildability. Therefore, $1 \%$ superplasticiser was selected as a control to investigate the effect of retarder dosage.

Fig. 11 and Fig. 12 show the results of the open time influenced by varying retarder dosage from 0 to $2.0 \%$ by weight of binder. All mixes in this series contained $1 \%$ superplasticiser.

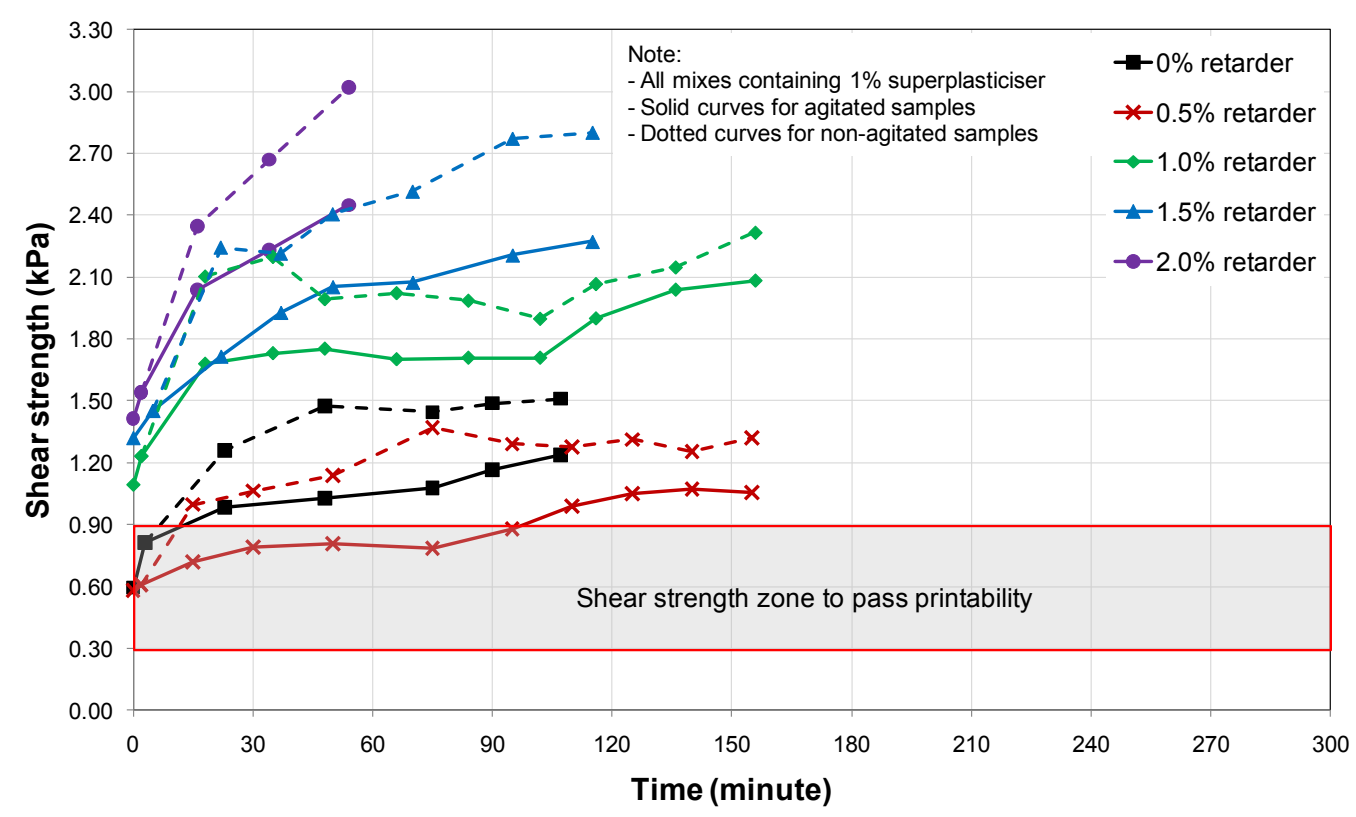

Fig. 11. Effect of retarder dosage on workability with time 


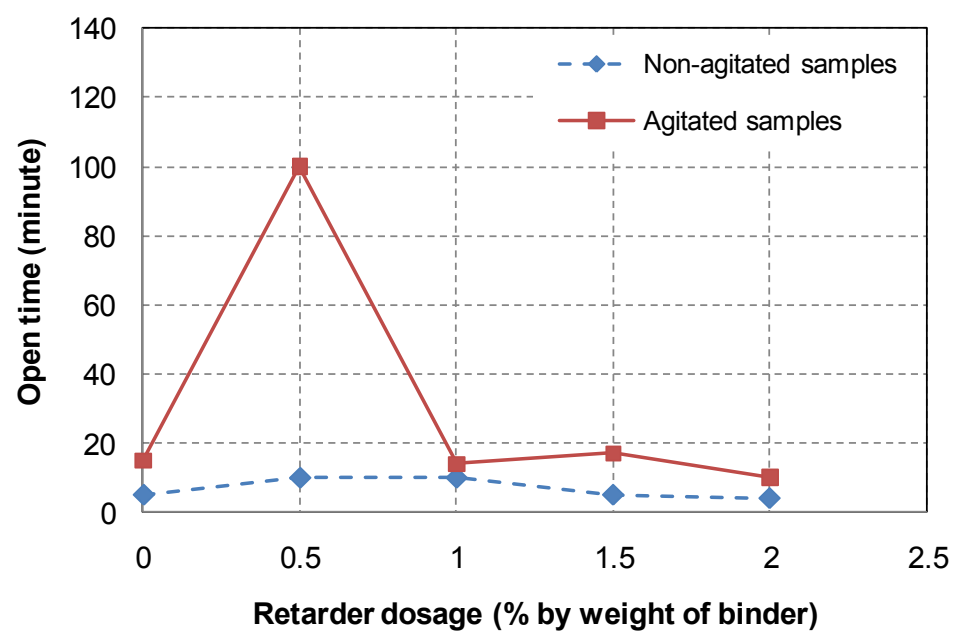

Fig. 12. Retarder dosage versus open time

For the non-agitated samples, the results showed that adding retarder did not influence the open time significantly. After less than 10 minutes the shear strength of all samples increased over $0.3 \mathrm{kPa}$, and the same phenomenon was observed in the mix without retarder, see Figs. 9 and 10 (dotted curves).

For the agitated samples, the open time was extended significantly to 100 minutes when $0.5 \%$ retarder was added. However, increasing the dosage beyond $0.5 \%$ appeared to decrease it. $1 \%$ retarder increased the shear strength by $0.3 \mathrm{kPa}$ after 14 minutes but after that it increased slowly for 90 minutes by another $0.3 \mathrm{kPa}$. The retarder appeared not to be effective in extending the open time with the mixes having low initial workability (i.e. high shear stress). Another disadvantage of $1.0 \%$ to $2.0 \%$ retarder was that it reduced the one day strength significantly, to less than $1 \mathrm{MPa}$, while up to $20 \mathrm{MPa}$ was found at one day with $0.5 \%$ retarder. Therefore, $0.5 \%$ retarder combined with $1.0 \%$ superplasticiser was identified as the optimum in terms of open time.

\subsection{Buildability}

The buildability of the optimum mix in terms of extrudability, workability and open time $(0.5 \%$ retarder with a 100 minute open time) was examined to find the optimum by varying the dosage of superplasticiser which resulted in different shear strength of the fresh concrete. The results confirmed that outside of $0.3-0.9$ 
$\mathrm{kPa}$ shear strength the concrete could not build a test sample due to being either too wet or too stiff (Fig. 13). A mix with $0.3 \mathrm{kPa}$ shear strength could only build 4 layers for a 1 filament group and 7 layers for a 5 filament group and the filaments were deformed considerably. A mix with $0.9 \mathrm{kPa}$ shear strength could not build 2 layers correctly as some broken points occurred in the filaments. The optimum mix in terms of buildability was again one with a $0.55 \mathrm{kPa}$ shear strength as it could build up to 15 layers for a one-filament group and up to 34 layers for a fivefilament group, see Fig. 13. Indeed 57, 60, 61 and 61 layers could be attained for 2, 3, 4 and 5 filament groups, respectively, with only one filament in each group collapsing (Fig. 14).

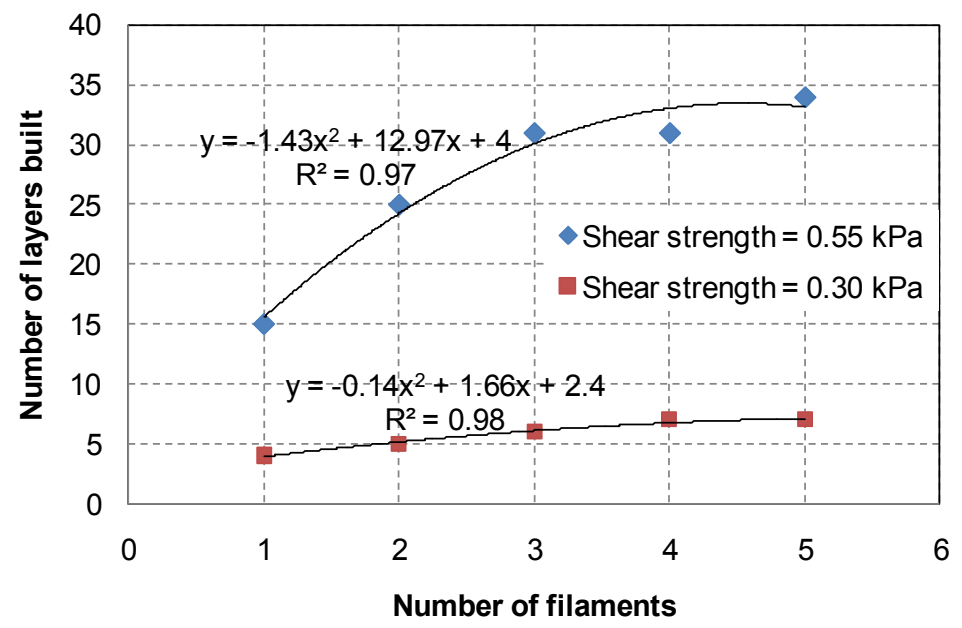

Fig. 13. Effect of workability on buildability

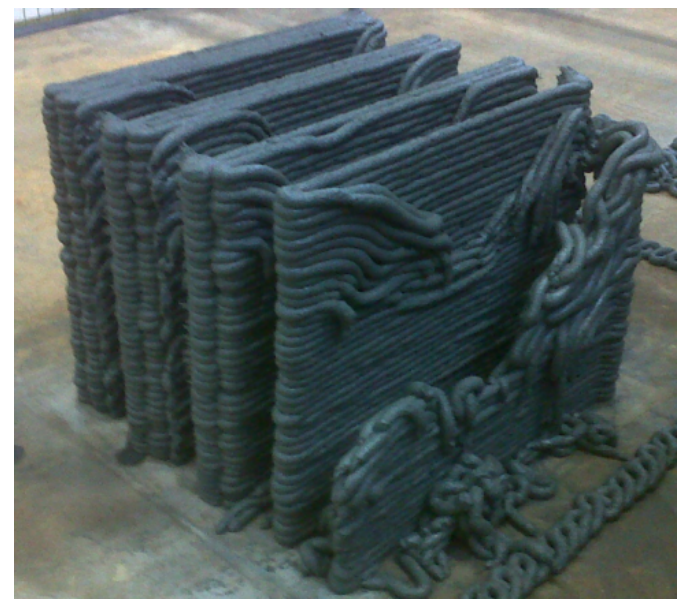

Fig. 14. The buildability of a $0.55 \mathrm{kPa}$ shear strength concrete mix 


\subsection{Optimum mix proportions}

Five trial mixes were designed to identify optimum mix proportions for printing concrete. The extrudability tests showed that Mix 4 (water to binder ratio of 0.26 ) was best suited to printing freeform components, which had a 60:40 sand:binder ratio, comprising $70 \%$ cement, $20 \%$ fly ash and $10 \%$ silica fume, plus $1.2 \mathrm{~kg} / \mathrm{m}^{3}$ micro polypropylene fibres. This mix also needed $1 \%$ superplasticiser and $0.5 \%$ retarder to attain an optimum workability of $0.55 \mathrm{kPa}$ shear strength, an optimum open time of up to 100 minutes and the ability to build a large number of layers with various filament groups. The compressive strength of this mix, determined by casting $100 \mathrm{~mm}$ cube specimens, was measured at 1, 7,28 and 56 days in accordance with BS EN 12390-2:2009 [20], and found to be 20, 80, 110 and 125 $\mathrm{MPa}$, respectively.

\subsection{Printing a full-scale component}

The results of the above laboratory tests provide empirical evidence of the fresh concrete properties necessary to print concrete with the prototype printing machine. However, production of a full size component was necessary to demonstrate if the proposed criteria and mix design are suitable in practice. To achieve this, a multi-cellular curved bench was printed using the proposed optimum mix.

A 3D model of the bench was designed by computer as shown in Fig. 15 before being printed layer-by-layer. The printed component was $2 \mathrm{~m}$ long, $0.9 \mathrm{~m}$ maximum width and $0.8 \mathrm{~m}$ high and comprised 128 layers of $6 \mathrm{~mm}$ thickness, see Fig. 16. The form of the bench is deliberately architectural to show the possibilities when fabricating a component using this novel concrete printing process (compared with traditional construction methods). It has since been exhibited in two international events. 


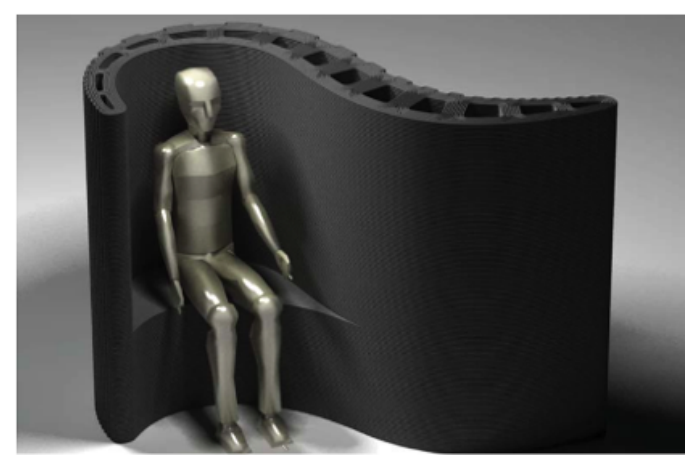

Fig. 15. The 3D model bench

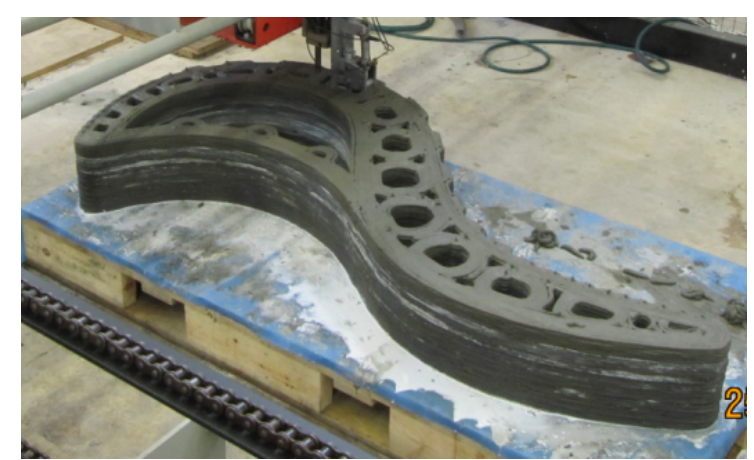

Fig. 16. The bench being printed

\section{Conclusions}

A high-performance printing concrete has been developed for an innovative printing process which is a digitally-controlled additive manufacturing method which can build architectural and structural components without formwork, unlike conventional concrete construction methods. The critical fresh properties of such a concrete are extrudability and buildability, which have mutual relationships with the workability and the open time of concrete mix. Definitions and test methods are presented to evaluate these fresh properties which have then been shown to provide reliable indications of the performance of a range of mixes (with a maximum aggregate size of $2 \mathrm{~mm}$ ).

The optimum mix was found to have a 3:2 sand to binder ratio with the latter comprising $70 \%$ cement, $20 \%$ fly ash and $10 \%$ silica fume plus $1.2 \mathrm{~kg} / \mathrm{m}^{3}$ of $12 / 0.18 \mathrm{~mm}$ length/diameter polypropylene fibres. This mix had a water to binder ratio of 0.26 together with a superplasticiser and retarder with dosages of $1 \%$ and $0.5 \%$ by weight of binder. This mix could be printed through a $9 \mathrm{~mm}$ diameter nozzle with consistent filaments to build up to 61 layers in one session without noticeable deformation of bottom layers. The open time extended up to 100 minutes. The compressive strength of concrete exceeded the target set, being 110 $\mathrm{MPa}$ at 28 days

The suitability of the proposed definitions of extrudability and buildability and associated test methods, as well as the optimised mix, have been validated by the manufacture of a full-scale freeform component with proportions commensurate 
with the likely dimensions of potential construction products such as cladding and wall panels.

\section{Acknowledgements}

This project is funded by Engineering and Physical Sciences Research Council of the UK (EPSRC) Grant (EP/E002323/1) through the IMCRC at Loughborough University. The authors gratefully acknowledge the supply of materials from Weber (St Gobain), Hanson Cement, BASF and Grace Construction Products and the assistance in designing the freeform components from Foster + Partners and Buro Happold. The authors are also grateful for the laboratory assistance of John Webster, Jonathan Hales and David Spendlove.

\section{References}

[1] Okamura H, Ouchi M (2003) Self-compacting concrete. Journal of Advanced Concrete Technology 1: 5-15

[2] RILEM Technical Committee (2006) Final report of RILEM TC 188-CSC 'Casting of self compacting concrete'. Materials and Structures 39:937-954

[3] Austin S A, Robins P, Goodier C I (1999) The rheological performance of wet-process sprayed mortars. Magazine of Concrete Research 51:341-352

[4] Austin S A, Robins P, Goodier C I (2002) Construction and Repair with Wet-Process Sprayed Concrete and Mortar, Technical Report 56. The Concrete Society UK

[5] Buswell R, Soar R C, Gibb A, Thorpe T (2007) Freeform construction: Mega-scale rapid manufacturing for construction. Automation in Construction 16:224-231

[6] Lim S, Le T, Webster J, Buswell R, Austin S, Gibb A, Thorpe T (2009) Fabricating construction components using layer manufacturing technology. Proceedings of International Conference on Global Innovation in Construction, Loughborough, UK, pp. 512-520

[7] Austin S, Robins P, Goodier C I (2005) Low-volume wet-process sprayed concrete: pumping and spraying. Materials and Structures 38:229-237

[8] Jacobsen S (2009) Flow conditions of fresh mortar and concrete in different pipes. Cement and Concrete Research 39:997-1006

[9] Mu B et al. (1999) Cementitious composite manufactured by extrusion technique. Cement and Concrete Research 29:237-240

[10] Shao Y et al. (2011) Microstructure of extruded cement-bonded fibreboard. Cement and Concrete Research 31:1153-1161

[11] Lombois-Burger $\mathrm{H}$ et al. (2006) Kneading and extrusion of dense polymer-cement pastes.

Cement and Concrete Research 36:2086-2097

[12] Tattersall G H, Banfill P F G (1983) The rheology of fresh concrete. Pitman Books Ltd., London

[13] British Standards Institution (1990) BS 1377-9:1990 Methods of test for soils for civil engineering purposes. Milton Keynes, UK 
[14] Previte R W (1977) Concrete slump loss. ACI materials journal 74:361-367

[15] Ravina D et al. (1994) Slump loss and compressive strength of concrete made with WRR and HRWR admixtures and subjected to prolonged mixing. Cement and Concrete Research 24:14551462

[16] Kim B G, Jiang S P, Aitcin P C (2000) Slump improvement mechanism of alkalies in PNS superplasticized cement pastes. Materials and Structures 33:363-369

[17] Alhozaimy M A (2009) Effect of absorption of limestone aggregates on strength and slump loss of concrete. Cement and Concrete Composites 31:470-473

[18] Le T, Soutsos M N, Millard S G, Barnett S J (2007) UHPFRC - Optimisation of mix proportions. Proceedings of concrete platform international conference, Belfast, UK, pp. 339-348. [19] Tarmac Limited (2007) CEMROK 40A - Product information

[20] British Standards Institution (2009) BS EN 12390-3:2009 Testing hardened concrete. Milton Keynes, UK 